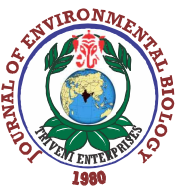

\title{
Speciation of heavy metals and their distribution in surface sediments of the northwestern part of the ROPME Sea Area
}

\author{
H. Alshemmari ${ }^{1 *}$ L. Talebi $i^{1}$ and M.N.V. Subrahmanyam ${ }^{12}$ \\ 'Environmental Pollution and Climate Program, Environment and Life Sciences Research Center, Kuwait Institute for Scientific Research, \\ Safat-13109, Kuwait \\ ${ }^{2}$ Head Quarters, Regional Organization for the Protection of the Marine Environment (ROPME), Safat-13124, Kuwait \\ *Corresponding Author Email : hshamari@kisr.edu.kw
}

\section{Abstract}

Aim: To analyze samples of marine sediment at 24 stations for heavy metals as per sequential Community Bureau of Reference protocol in order to obtain metal distribution pattern in Kuwait offshore

Methodology: In the present study, a centrifugal particle-size analyzer was used for measuring sediment grain size. The Community Bureau of Reference scheme was deployed for the sequential extraction of heavy metal speciation, and the fractionation was determined by Inductively Coupled Plasma-Mass Spectrometry.

Results : Grain-size analysis showed that the study area contained $71.8 \%$ silt, $22.6 \%$ sand and $5.56 \%$ clay at most locations. The average abundance of total concentration of heavy metals was found in the following order: lead $<$ cobalt $<$ copper $<$ zinc $<$ chromium $<$ nickel. The mobility order of exchangeable fraction of heavy metals decreased in the order lead $>$ nickel> zinc $>$ cobalt> copper; in the reducible fraction: lead> copper> zinc > cobalt> nickel; in the oxidizable fraction: lead> chromium> copper> nickel $>$ cobalt $>$ zinc and in the

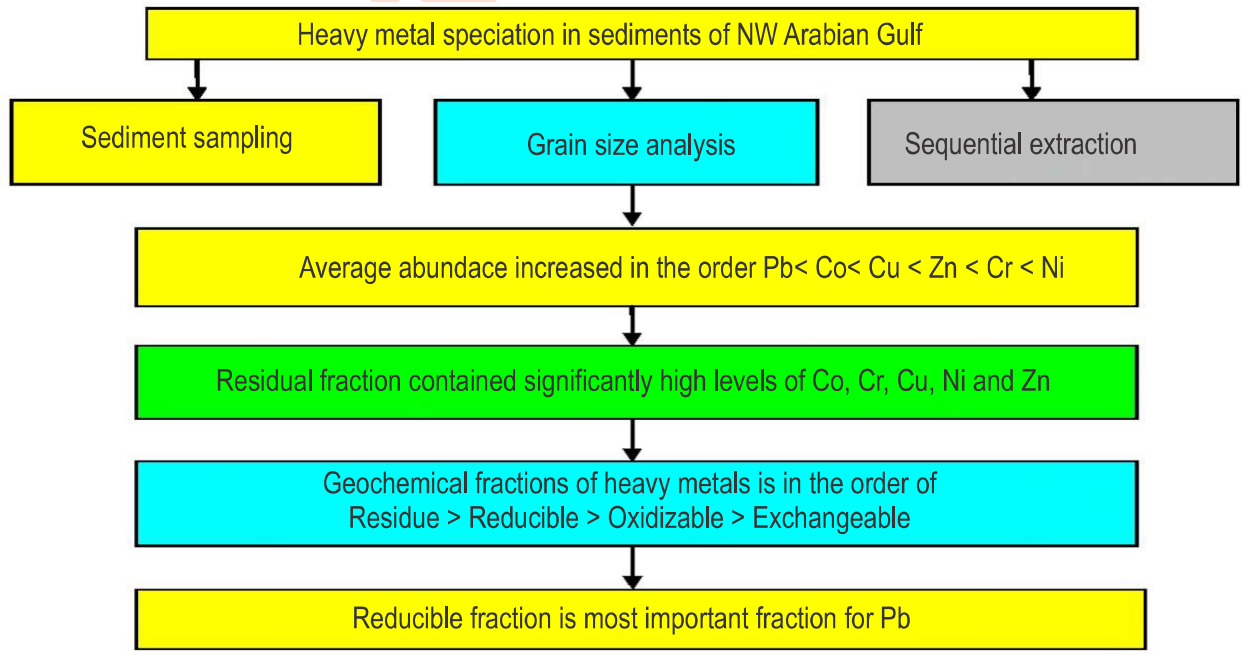
residual fraction:cobalt> chromium $>$ nickel $>$ zinc $>$ copper $>$ lead, respectively.

Interpretation: The outcome of the present study cannot establish the actual form of species of a given metal in the sediment; though, it appears to be useful in categorizing the metals within several prevailing geochemical fractions.

Key words: Geochemical fractions, Grain-size, Heavy metals, Kuwait offshore, Sediment

How to cite : Alshemmari, H., L. Talebi and M.N.V. Subrahmanyam: Speciation of heavy metals and their distribution in surface sediments of the northwestern part of the ROPME SeaArea. J. Environ. Biol., 41, 101-110 (2020). 


\section{Introduction}

Heavy metals are also considered as trace elements because of their presence in trace amount ( $>10 \mathrm{ppm}$ ) in various environmental matrices. Metals are highly persistent environmental pollutants (McAloon and Mason, 2003). The bioavailable metal load in sediments may alter the distribution and composition of benthic group (Caplat et al., 2005), resulting in bioaccumulation of these pollutants in different organisms. Thus, their tendency to remain as an environmental contaminant for a long period and to get magnified through food chain is high. Environmental contamination and exposure to heavy metals is a serious problem throughout the world. Human exposure to heavy metals has risen dramatically in the last 50 years as a result of an exponential increase in the use of heavy metals in industrial processes and products (Bharti, 2012). Several studies have been conducted to investigate the sources and distribution of heavy metals in Kuwait's territorial waters (Al-Shamroukh et al., 2005). Toxic trace metals are common in industrial and domestic effluents where their levels are commonly elevated due to anthropogenic use (Al-Muzaini, 2002).

Accumulation of metals in sediments from both natural and anthropogenic sources occur as standpoint, consequently making it challenging to understand and conclude the source of heavy metals present in the sediments (Idris et al., 2007). In recent years, industrial activities has led to increased concentrations of trace metals from terrestrial sources toward the aquatic environment (Lulin et al., 2015). The importance of metal speciation research in environmental studies stem from the need to understand the role of metal species in terms of bioavailability, bioaccumulation, mobility and persistence in the environment. It is now widely accepted that the role of sediments as a sink for metal pollutants cannot be fully assessed by measuring the total metal concentration (Islam et al., 2015). Speciation analysis in different oxidation states or chemical forms of a particular heavy metal can be defined as the separation and quantification of heavy metal species.

Today, while performing generic environmental risk assessment of heavy metals or evaluating the environmental impact of heavy metals in a defined geographical area, it is not only sufficient to determine the total heavy metal concentrations but also essential to quantify the chemical forms of heavy metals in the sediment using speciation techniques in order to evaluate their impact on the aquatic system, because some sediment components, such as oxy-hydroxides of manganese and iron and organic matter are particularly important in terms of their scavenging ability and can influence the composition, distribution and bioavailability of heavy metals within sediment (Katip et al., 2012). Although determination of each species is an important task, the concentration of various species is more significant in setting environmental and ecological standards. Consequently, studies are being done to find the association of metals with different geochemical phases. The change in ecosystem will drive the change in physico-chemical parameters within the environment and can influence the process and dynamics of heavy metals caused by change in interaction pattern of metals and environment (Najamuddin and Surahman, 2017). Though sequential extraction procedure is complicated and lengthy, it provides adequate information related to the origin, occurrence, biological/physico-chemical aspects, mobilization and transport of metals (Saleem et al., 2015). Investigations have been made for estimating the quantities of heavy metals associated with different fractions of sediments to develop chemical extraction speciation techniques (Chester et al., 1988).

The Community Bureau of Reference (BCR) sequential extraction procedure is widely applied to assess heavy metal mobility in sediment (Li et al., 2010). Sequential extractions are useful in identifying different sources of contamination, and in obtaining additional information on the solubility of secondary minerals formed by pyrite oxidation. Thus, the effectiveness of $\mathrm{BCR}$ procedure has proved to be a useful tool for predicting shortand long-term mobility of trace elements, even in complex environmental scenarios. In light of the above, the objective of the current study was to evaluate marine sediment samples for metal distribution pattern in Kuwait offshore following the BCR protocol.

\section{Materials and Methods}

Sample collection and storage: In total 24 sediment samples were collected from Kuwait's offshore marine environment $\left(28^{\circ} 72^{\prime} \mathrm{N}, 48^{\circ} .40^{\prime} \mathrm{E}\right)$ from north to south covering 24 locations (Fig. 1) of the inner ROPME (Regional Organization for the Protection of the Marine Environment) Sea Area. ROPME Sea Areas divided into three areas: (i) inner, (ii) middle, and (iii) outer sea areas. The study area herein lies within the inner ROPME Sea Area. The samples were cut with a gravity corer into small pieces were further divided into sub-samples. Two of these subsamples were transferred to separate pre-weighed polytetrafluorethylene centrifuge tubes for total element analysis and sequential extraction, respectively. The remaining samples were used to conduct a supplementary analysis.

Grain size analysis: A Shimadzu SA-CP3 centrifugal particlesize analyzer was used for analysis of sediment grain size for classification and identification of sediment texture followed the protocol of Romano et al., 2017. In total 24 surface sediment samples were analyzed for determining grain size distribution. Dried sediment samples of $20 \mathrm{~g}$ each were placed in a $50 \mathrm{ml}$ beaker and suspended in $0.5 \%$ sodium hexametaphosphate solution. The samples were sieved through $63 \mu \mathrm{m}$ sieve to separate sand from silt and clay. The sand retained on the sieves were dried at $105^{\circ} \mathrm{C}$ were weighed, while the suspension was collected and analyzed with Shimadzu SA-CP3 particle size analyzer. Data obtained from the analysis of coarse and fine fraction was integrated and processed for calculating the percentage of main grain size fractions (sand, silt, clay), and also to reconstruct the frequency and the cumulative curves and to obtain the main statistical parameters. 
Concentration of heavy metals: To determine the concentration of total heavy metals, sediment samples were subjected to microwave digestion following MOOPAM (2010) procedure. The concentrations of $\mathrm{Co}, \mathrm{Cr}, \mathrm{Cu}, \mathrm{Ni}$ and $\mathrm{Zi}$ in sediments were determined by inductively coupled plasma optical emission spectrometry (ICP-OES) and inductively coupled plasma massspectrometry (ICP-METALS).

Sequential extraction of heavy metals: The BCR (Community Bureau of Reference) three-step scheme of the European Commission Standards, Measurements and Testing Program BCR-701 (Ure et al., 1993) was used for the sequential extraction procedure (SEP) to analyze heavy metal speciation. The fractionation of heavy metals was determined by ICP-METALS. The sequential extraction procedure was conducted by analyzing four samples of certified reference material (CRM) of BCR-701. The accuracy of measured concentrations of each heavy metal in the CRM was compared with their certified or 'true' values. A further check on data quality was performed by comparing with a directly measured total heavy metal concentration.

\section{Results and Discussion}

The results of heavy metal speciation by BCR three step extraction procedure are presented in Fig. 2 and 3 for 2421 stations for six heavy metals. The order of allied $\mathrm{Cr}$ fractions at all station is: Residue> Reducible> Oxidizable> Exchangeable. Compared with $\mathrm{Co}, \mathrm{Cr}$ was richer in all fractions at all stations. The sum of four fractions for $\mathrm{Cr}$ agreed well with the total $\mathrm{Cr}$ analysis, except at Stations 1-5 and 7-9. The residual fraction accounted for more than $90 \%$ of total $\mathrm{Cr}$ at Station $6,10,11,12$, 13. The oxidizable fraction was the next most abundant fraction, forming up to about $5 \%$ to $25 \%$ of total $\mathrm{Cr}$. The reducible fraction accounted for $7-30 \%$ of total $\mathrm{Cr}$, with the highest concentration of $10.98 \mathrm{mg} \mathrm{kg}^{-1}$ at station 18, and the lowest of $0.29 \mathrm{mg} \mathrm{kg}^{-1}$ at station 23. Exchangeable $\mathrm{Cr}$ was the most poorly represented fraction, with a high of $1.48 \mathrm{mg} \mathrm{kg}^{-1}$ at station 18 , and a low of 0.12 $\mathrm{mg} \mathrm{kg}^{-1}$ at station 4. These results are in good agreement with the results of Morillo et al. (2004) and explain that $\mathrm{Cr}$ has a robust relationship with the crystalline sediments than with the nonlithogenous components.

The order of affiliated Co fractions at all stations and all depths is as follow: Residue> Reducible> Oxidizable> Exchangable. The residual fraction was predominant, accounted $45-95 \%$ of the total Co identified. In general, the oxidizable fraction accounted for $10 \%$ (sometimes more) of total Co. The reducible fraction was less than $2-35 \%$ of total $\mathrm{Co}$. The highest concentration was $2.23 \mathrm{mg} \mathrm{kg}^{-1}$ at station 1 ; while the lowest was $0.10 \mathrm{mg} \mathrm{kg}^{-1}$ at station 11, and at stations $10,15,16$ and 18; the reducible fraction was below the detection limit. The exchangeable fraction was the most poorly signified. Exchangeable fraction values at stations 10, 12, 15, 16, 18, 20 and 23 were below the detection limit. The concentration of cobalt is in agreement with the previous studies conducted at the East China Sea and the Turkish waters (Akcay et al., 2003) where Co was found mainly in the residual fraction, and their study exhibited only contaminated stations holding high non-residual fractions. The perusal of data associated with $\mathrm{Cu}$ fraction was found in the order: Residue> Reducible> Oxidizable> Exchangeable. The major portion of Cu was primarily held in the residual fraction, i.e., $57 \%$ of total $\mathrm{Cu}$, while the lowest of $2 \%$ was found at station 8 (Fig. 2). Exchangeable $\mathrm{Cu}$ was the least perceived fraction, and the maximum transpired $\mathrm{Cu}$ concentration in exchange able fraction was $1.48 \mathrm{mg} \mathrm{kg}^{-1}$ at station 6 and lowest at stations 10,11, 12 and 16 (less than $1.0 \%$ in all cases). High proportion of residual fraction of $\mathrm{Cu}$ is similar to the findings from Spain, China and Singapore (Morillo et al., 2004).

The sum of four fractions of Ni concentration agrees well with the total Ni concentration (Fig.3). The direction of four fractions linked for $\mathrm{Ni}$ concentration is: Residue> Reducible> Oxidizable> Exchangeable. The highest concentration of $\mathrm{Ni}$ was found at station $1\left(15 \mathrm{mg} \mathrm{kg}^{-1}\right)$, and the lowest $\left(0.19 \mathrm{mg} \mathrm{kg}^{-1}\right)$ at station 6 . The oxidizable fraction accounted for $15.42 \%$ of total detected Ni. The highest concentration $\left(12.76 \mathrm{mg} \mathrm{kg}^{-1}\right)$ was found at station 2, while the lowest was $\left(1.18 \mathrm{mg} \mathrm{kg}^{-1}\right)$ found at station 24. This study shows that $\mathrm{Ni}$ was found mainly in the residual fraction and revealed that $\mathrm{Ni}$ usually has a stronger association with crystalline sediments than with the non-lithogenous components. Similar results of marine sediments were reported from Spain and Singapore by Morillo et al. (2004).

The sum of four fractions of $\mathrm{Pb}$ agrees with the total concentration, except at station 16 (Fig. 3). The order of associated fraction was in the order: Reducible> Residue> Oxidizable> Exchangeable. The highest concentration $(2.19 \mathrm{mg}$ $\left.\mathrm{kg}^{-1}\right)$ was observed at station 6 , and the lowest $\left(0.57 \mathrm{mg} \mathrm{kg}^{-1}\right)$ at station 13. The exchangeable fraction was least and at most stations was below the detection limit. The highest concentration of exchangeable fraction $\left(0.48 \mathrm{mg} \mathrm{kg}^{-1}\right)$ was found at station 7 , and the lowest $(0.31 \mathrm{mg} / \mathrm{kg})$ at station 8 . This indicates that much of the $\mathrm{Ni}$ present is weakly bound to the sediments. High proportion of reducible fraction and small residual fraction together is consistent with the anthropogenic origin of the samples of this study. In a similar study carried out in Spain, Singapore and Australia Morillo et al. (2004) demonstrated that the reducible fraction is formed in the non-residual fractions. In the present study, lead existed in higher concentrations in reducible fractions than in oxidizable fractions and agrees well with other studies (Han et al., 2015; Cuvier et al., 2016) probably due to the fact that lead can form stable complexes with Fe and $\mathrm{Mn}$ hydrous oxides. The reducible fraction is unstable and can be released into the marine environment due to changes in redox potential (Morillo et al., 2004; Guven and Akinci, 2008).

The order of $\mathrm{Zn}$ accumulated fractions is as follows: Residue $>$ Reducible> Oxidizable> Exchangeable. The residual fraction was the most dominant fraction and accounted $65 \%$ of the total zinc detected. This study showed $\mathrm{Zn}$ was found in the residual fraction and is usually associated with crystalline sediments than with the non-lithogenous components. These results are similar to 


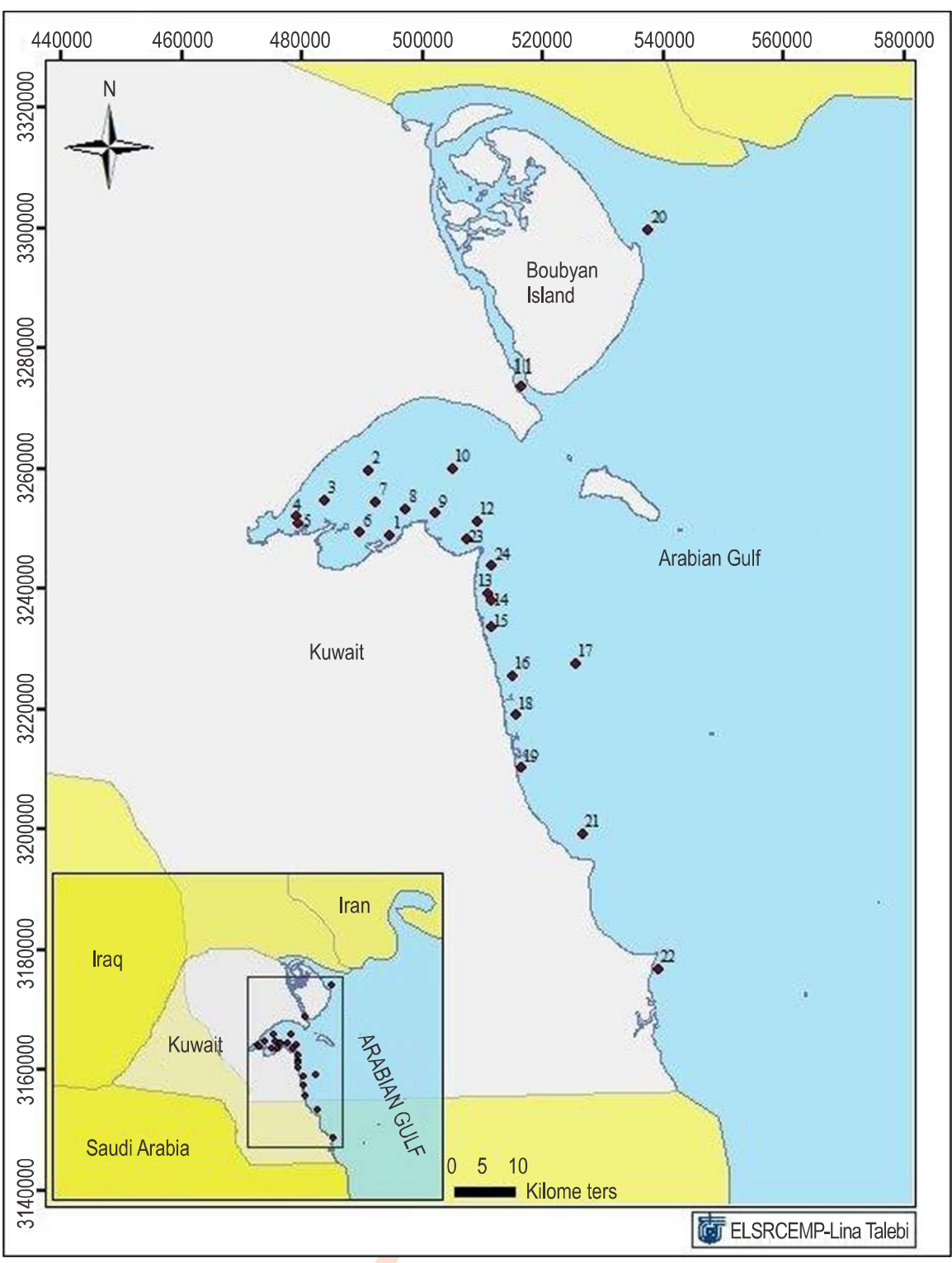

Fig.1: Map showing the sampling locations along the Kuwait offshore marine environment.

the results of marine sediments from Spain and Singapore (Morillo et al., 2004). To assess the environmental impact of sediments contaminated with heavy metals, it is essential to understand the distribution of heavy metals among the different geochemical fractions (Qiao et al., 2013). Chen et al. (2018) suggested that the spatial distribution patterns of heavy metals showed that bioavailable fractions were higher in the residual fractions, while Cu concentrations in exchangeable and carbonate fractions were relatively higher than those in the bioavailable fractions. It is the fraction, in which a heavy metal is bound that determines its behaviour; in particular, its bioavailability and mobilization capacity. The BCR sequential extraction technique used in this study by separating heavy metals into four fractions are as follows: exchangeable, reducible, oxdizable and residual. After fractionation, there were wide variations in the proportions of heavy metals; $\mathrm{Co}, \mathrm{Cr}, \mathrm{Cu}, \mathrm{Ni}$, and $\mathrm{Zn}$ within each of the four fractions. The results of $B C R$ sequential extraction technique showed that partitioning of heavy metals in contaminated sediments in different parts of Kuwait waters was different from that of uncontaminated sediments. Exchangeable heavy metals are bioavailable and most dangerous speciation fractions for the marine environment because they are weakly bound and equilibrate easily and rapidly with the water column (Morillo et al., 2004). This is due to electrostatic interaction of heavy metals on 


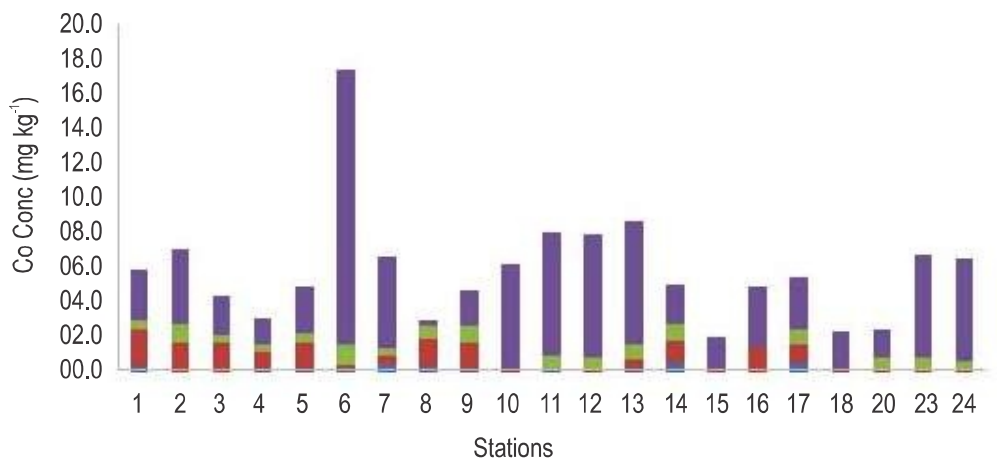

- Residue $\left(\mathrm{mg} \mathrm{kg}^{-1}\right)$ - Oxidizable $\left(\mathrm{mg} \mathrm{kg}^{-1}\right)$ Reducible $\left(\mathrm{mg} \mathrm{kg}^{-1}\right)$ Exchangable $\left(\mathrm{mg} \mathrm{kg}^{-1}\right)$

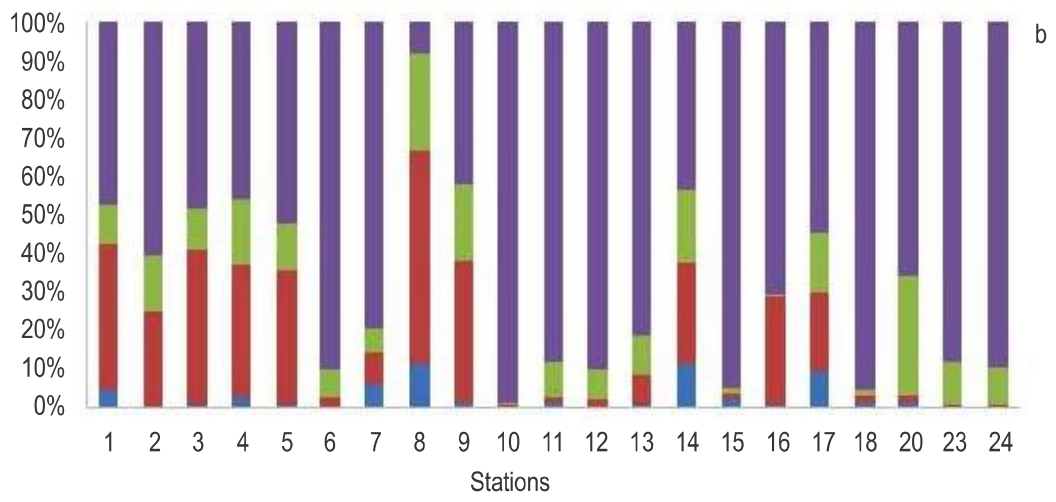

-Residue $\left(\mathrm{mg} \mathrm{kg}^{-1}\right)$ Oxidizable $\left(\mathrm{mg} \mathrm{kg}^{-1}\right)$ Reducible $\left(\mathrm{mg} \mathrm{kg}^{-1}\right)$ Exchangable $\left(\mathrm{mg} \mathrm{kg}^{-1}\right)$

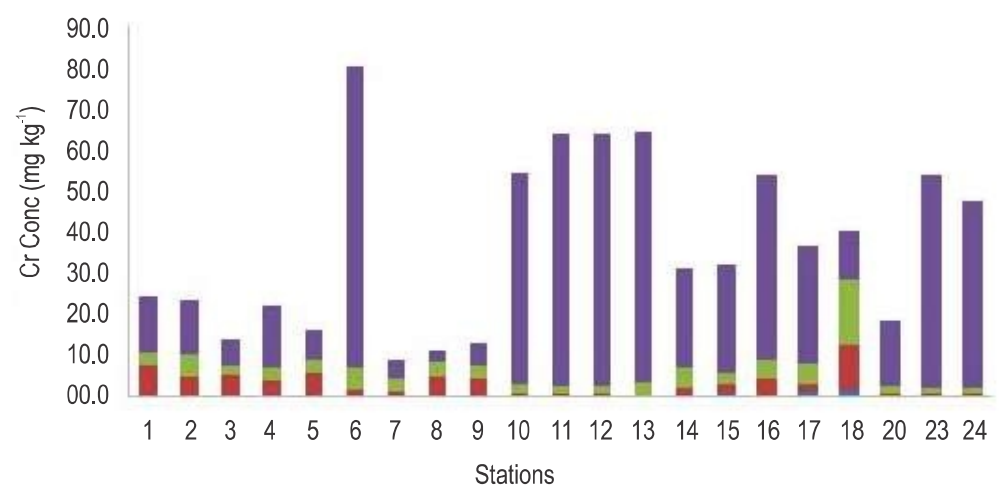

-Residue $\left(\mathrm{mg} \mathrm{kg}^{-1}\right)$ Oxidizable $\left(\mathrm{mg} \mathrm{kg}^{-1}\right) \quad$ Reducible $\left(\mathrm{mg} \mathrm{kg}^{-1}\right) \quad$ Exchangable $\left(\mathrm{mg} \mathrm{kg}^{-1}\right)$

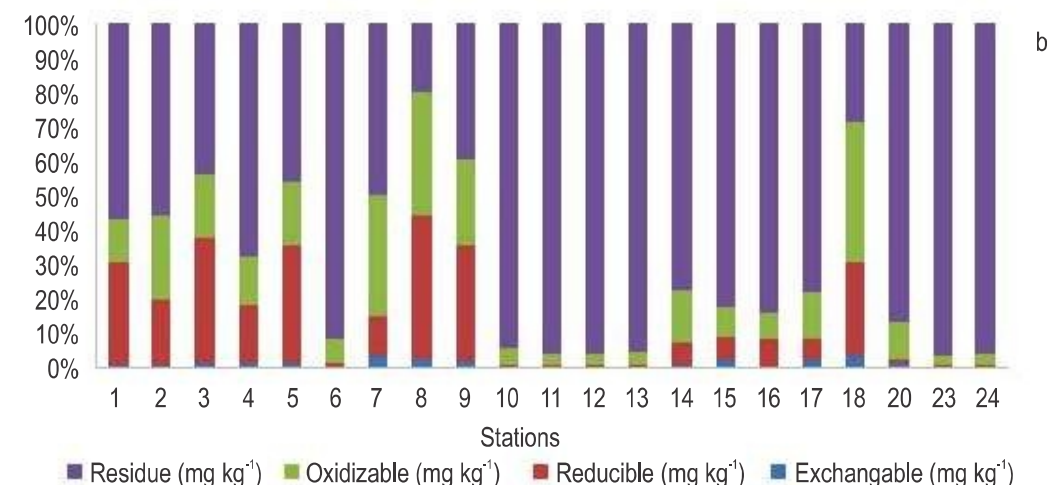



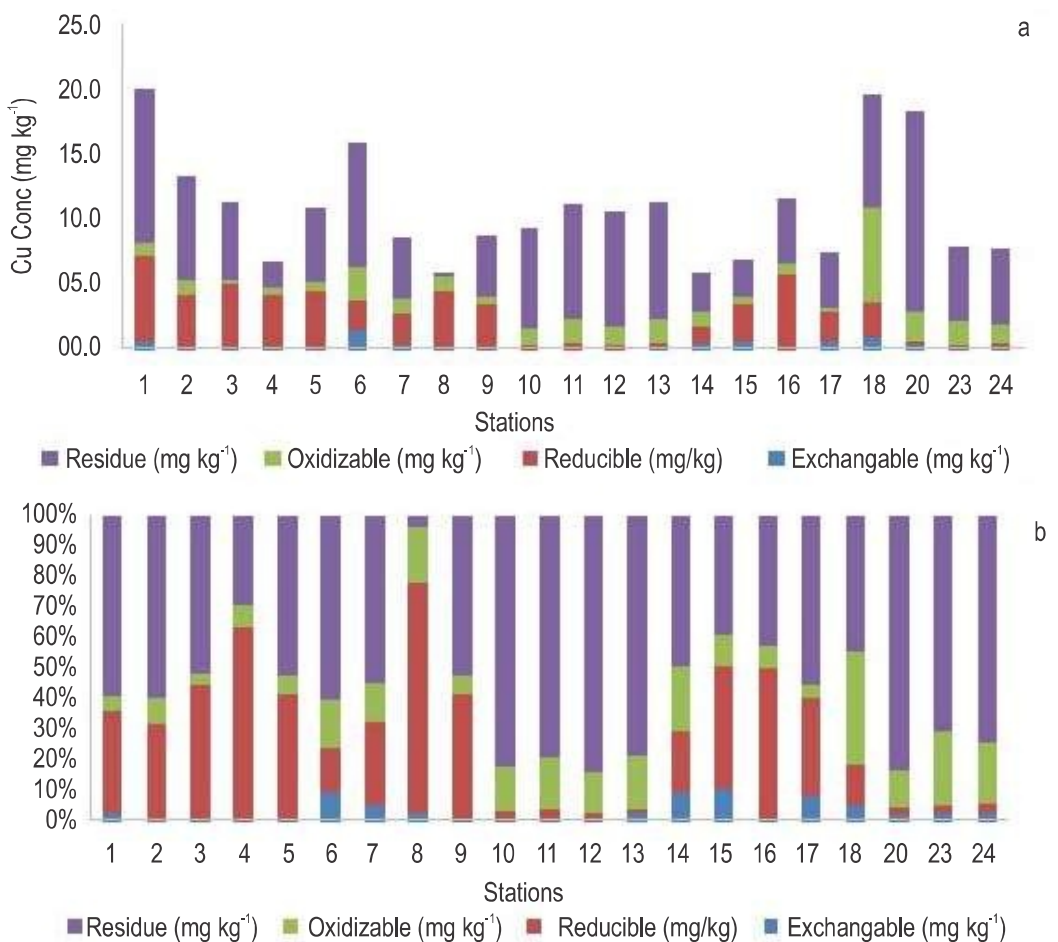

Fig. 2 : Absolute concentration (a) and percentage distribution (b) cobalt, chromium and copper in geochemical phases in sediments.

particle surfaces in exchangeable fraction (Ure et al., 1995). In this, elevated concentration of heavy metals in exchangeable fraction can be considered as an indicator of pollution, and can be regarded as a pollution indicator.

The mobility order of heavy metals in the exchangeable fraction decreased in the order $\mathrm{Pb}>\mathrm{Ni}>\mathrm{Zn}>\mathrm{Co}>\mathrm{Cu}>\mathrm{Cr}$. These results are similar to other studies carried out in Spain, Belgium and Singapore; they showed lowest $\mathrm{Cr}$ concentration in the exchangeable fraction. Low concentrations of exchangeable $\mathrm{Cu}$, Co, Zn, and Ni was less mobile and bio-available; whereas, a significant proportion of these heavy metals were very weakly bound. The results of the present study showed significant similarity with the previous work carried out in Spain during 2004 (Guevara-Rib et al., 2004).

The reducible fraction (iron oxides and hydroxides) for heavy metals is unstable under reducing conditions and occurs as coatings on detritus particles as cement between particles with high capacity for adsorption. The mobility order of heavy metals in the reducible fraction decreased in the order $\mathrm{Pb}>\mathrm{Cu}>\mathrm{Zn}>\mathrm{Co}>$ $\mathrm{Ni}>\mathrm{Cr}$. There were clearly observed trends in the concentration levels of $\mathrm{Pb}$ bound in the reducible fraction in the sediments (Fig.2). The reducible fraction was dominant for $\mathrm{Pb}$ at most stations, and the reducible fraction showed maximum $90 \%$ of total $\mathrm{Pb}$. There were clearly observed trends in the concentration levels of bound in the reducible fraction in the sediments (Fig.2). The reducible fraction was dominant at most stations, and the reducible fraction showed maximum of $90 \%$ of total. These findings are similar with previous studies (Hudson-Edwards et al., 1996; Morillo etal., 2004; Alshemmari et al., 2010).

The oxidizable fraction of heavy metals was bound to sulphides and organic matter with high heavy metal adsorptive capacity (Hlavay et al., 2004; Akcay et al., 2013). Heavy metals are recognized to be associated with organic matter, such as living organisms, organic detritus and coatings on mineral particles and may be available in marine environment where these are oxidized. In the present study, the mobility order of heavy metals in the oxidizable fraction decreased in the order $\mathrm{Pb}>\mathrm{Cr}>\mathrm{Cu}>\mathrm{Ni}>\mathrm{Co}>\mathrm{Zn}$ and showed very high amounts of total $\mathrm{Cr}$ and $\mathrm{Cu}$. This probably indicates association of $\mathrm{Cr}$ and $\mathrm{Cu}$ with organic matter. The oxidizable fraction also contained moderate amounts of $\mathrm{Ni}$ and low amounts of $\mathrm{Co}$ and $\mathrm{Zn}$. The heavy metals in residual fraction are characteristically composed of detrital silicates and resistant mineral fractions considered to be environmentally non-toxic under natural conditions, their release into the overlying water is unlikely (Morillo et al., 2004). The mobility order of heavy metals in the residual fraction decreased in the order $\mathrm{Co}>\mathrm{Cr}>\mathrm{Ni}>\mathrm{Zn}>\mathrm{Cu}>\mathrm{Pb}$. The concentration levels of $\mathrm{Co}$ and $\mathrm{Cr}$ bound in the residual fraction were especially significant (Fig.2). The residual fraction was predominant for both 

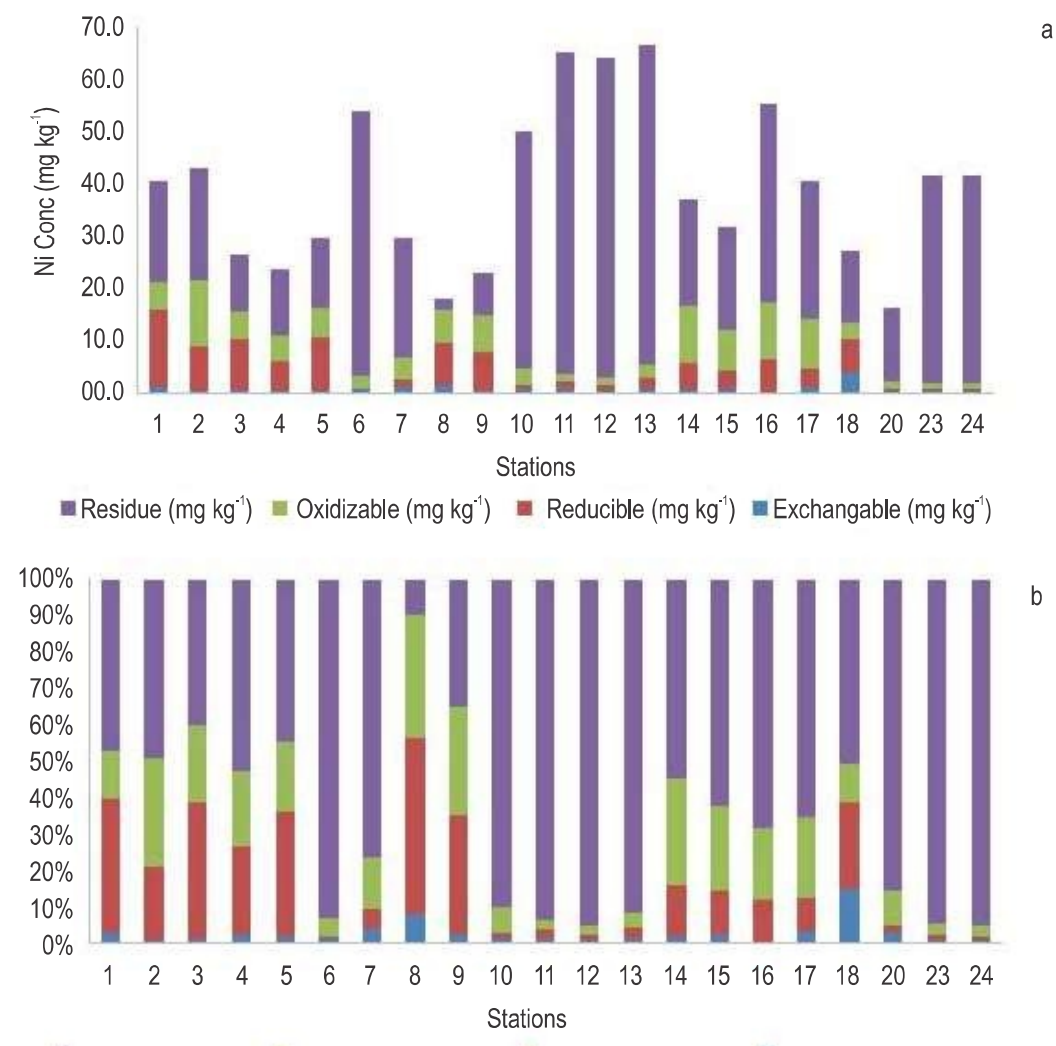

\#esidue $\left(\mathrm{mg} \mathrm{kg}^{-1}\right)$ = Oxidizable $\left(\mathrm{mg} \mathrm{kg}^{-1}\right)$ Reducible $\left(\mathrm{mg} \mathrm{kg}^{-1}\right)$ Exchangable $\left(\mathrm{mg} \mathrm{kg}^{-1}\right)$ 12.0

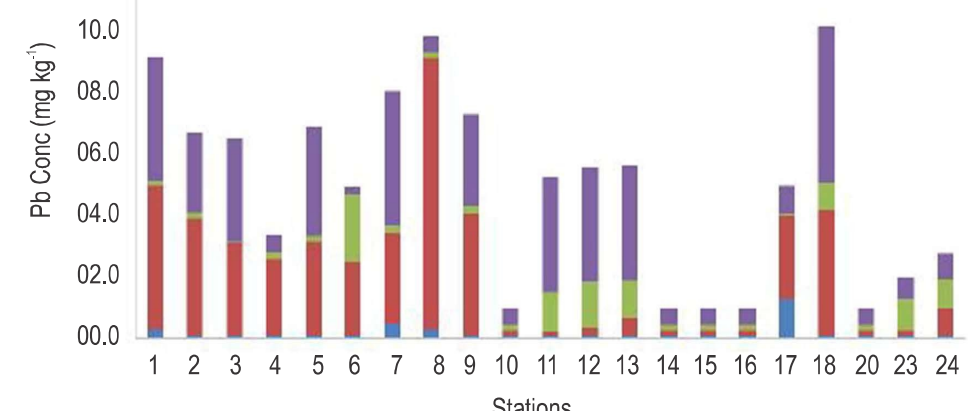

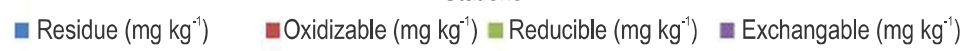

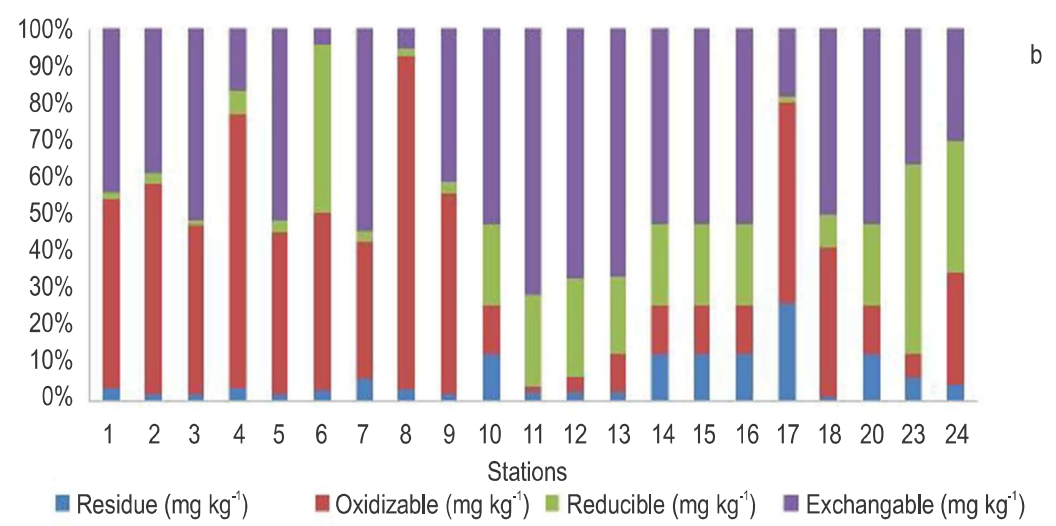



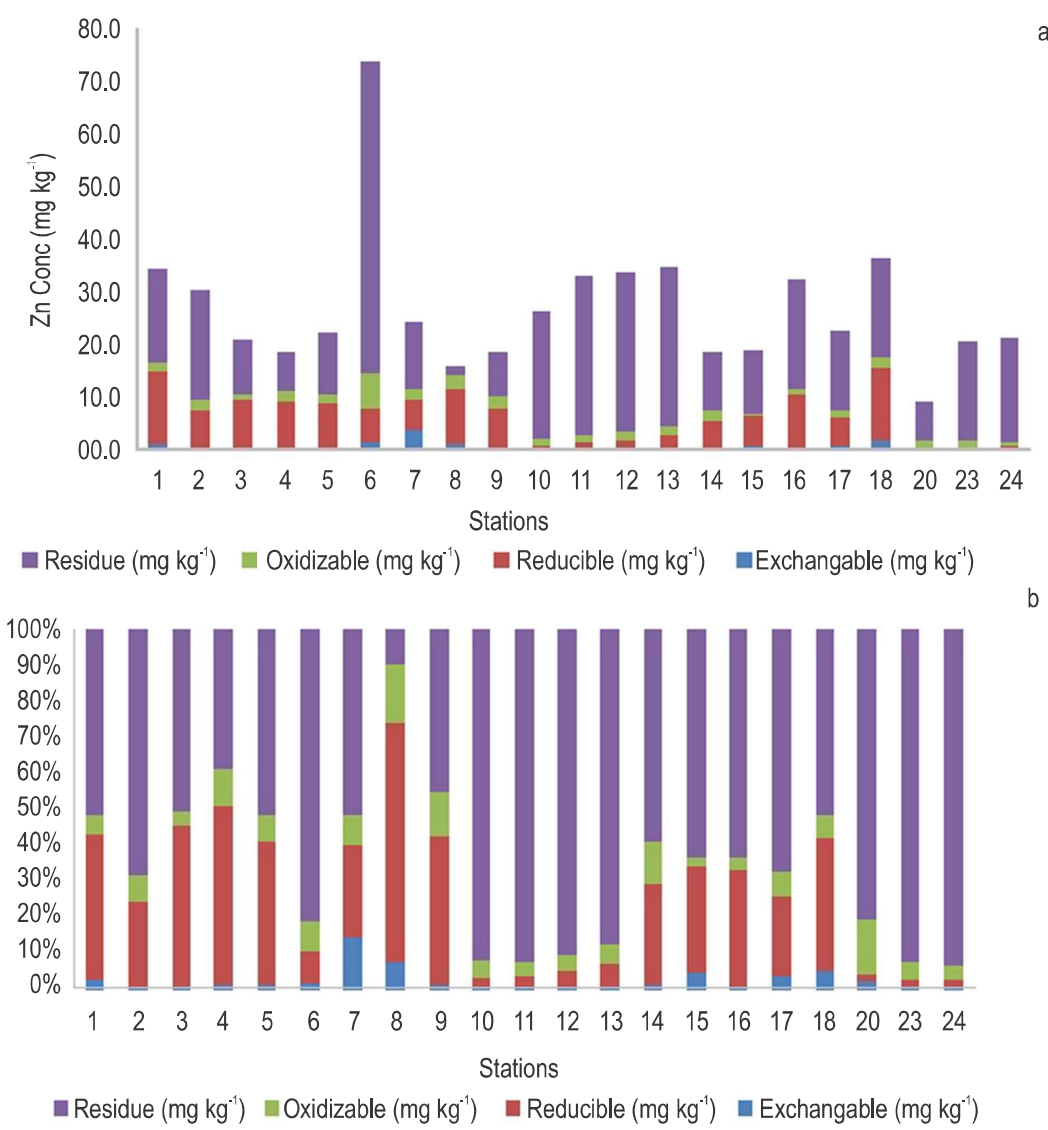

Fig. 3: Absolute concentration (a) and percentage distribution of (b) nickel, lead and zinc in geochemical phases in sediments.

Co (up to $90 \%$ of total $\mathrm{Co}$ ) and $\mathrm{Cr}$ (up to $90 \%$ of total $\mathrm{Cr}$ ). These findings are in agreement with the of previous studies reported from the East China Sea (Hlavay et al., 2004). The residual fraction was also predominant for both $\mathrm{Cu}(>90 \%$ of total $\mathrm{Cu}$ ) and $\mathrm{Ni}(>80 \%$ of total $\mathrm{Ni}$ ) (Fig.3) and was dominant in non-residual fractions $>10 \%$ of total, and these findings corroborates with the results of previous studies from the East China Sea. The average heavy metal abundance, based on total concentrations places $\mathrm{Pb}$ at the top followed by $\mathrm{Co}, \mathrm{Cu}, \mathrm{Zn}, \mathrm{Cr}$ and $\mathrm{Ni}$, respectively (Table 1). The distribution and enrichment of some selected heavy metals $(\mathrm{Cu}, \mathrm{Cr}, \mathrm{Ni}, \mathrm{Pb}$ and $\mathrm{Zn}$ ) in sediments collected from this study were assessed by calculating the index of geo-accumulation $\left(\mathrm{I}_{\text {geo }}\right)$, based on a background level of the "average shale". In addition, sediments from study area were also assessed as to compliance with international sediment quality guidelines.

$\mathrm{I}_{\text {geo }}$ values have been used to interpret sediment quality (Karbassi et al., 2008; Alshemmari et al., 2010); however, $I_{\text {geo }}$ is not readily comparable to other indices of enrichment due to the nature of $I_{\text {geo }}$ calculation, which involves a log function and a background multiplication of 1.5 (Abrahim and Parker, 2008; Alshemmari et al.,
2010). The $I_{\text {geo }}$ values of sampling sites in the present study are presented in Table 2. The $\mathrm{I}_{\text {geo }}$ values of $\mathrm{Co}, \mathrm{Cr}, \mathrm{Cu}, \mathrm{Ni}, \mathrm{Pb}$ and $\mathrm{Zn}$ indicated no pollution in sediment samples and were classified as unpolluted. The study pointed out a southward decreasing pattern in most heavy metal concentrations and the values of $\mathrm{Zn}, \mathrm{Co}$ and $\mathrm{Cr}$ were higher than the ones reported from Gulf Waters. The study pointed out a southward decreasing pattern in most heavy metal concentrations and the values of $\mathrm{Zn}, \mathrm{Co}$ and $\mathrm{Cr}$ were higher than the ones reported from some Worldwide Seas and Gulf Waters. In most cases, highest levels were documented within the bays and were related with in situ sediments, particularly that consisted of clays and very fine sands, and in areas typify with anthropogenic movements like desalination plants, oil spills, land filling, fishing boats and substantial litter and debris. In conclusion, the three-stage BCR sequential extraction procedure employed in this study cannot identify the actual forms of species of a given metal in the sediment; nevertheless, it appears to be useful in categorizing the metals within several general geochemical fractions. The results of the current investigation contribute valuable background for further research and management in the North West Arabian Gulf region. 
Table 1 : Total heavy metal concentrations ( $\mathrm{mg} \mathrm{kg}^{-1} \mathrm{dry}$ ) for surface sediments from Kuwait Marine Environment

\begin{tabular}{|c|c|c|c|c|c|c|c|}
\hline Sample \# & Depth (cm) & Co & $\mathrm{Cr}$ & $\mathrm{Cu}$ & $\mathrm{Ni}$ & $\mathrm{Pb}$ & $\mathrm{Zn}$ \\
\hline 1 & $0-3$ & 8.11 & 70.5 & 15.8 & 63.8 & 6.72 & 47.5 \\
\hline 2 & $0-3$ & 9.16 & 75.8 & 13.2 & 73.5 & 6.26 & 42.0 \\
\hline 3 & $0-3$ & 8.41 & 61.5 & 19.5 & 66.8 & 7.30 & 47.8 \\
\hline 4 & $0-3$ & 8.53 & 73.5 & 14.8 & 69.9 & 6.68 & 47.5 \\
\hline 5 & $0-3$ & 8.54 & 70.4 & 15.6 & 68.8 & 6.19 & 45.6 \\
\hline 6 & $0-3$ & 17.30 & 80.0 & 18.6 & 64.0 & 7.60 & 47.5 \\
\hline 7 & $0-3$ & 8.52 & 73.4 & 14.7 & 66.6 & 6.17 & 45.6 \\
\hline 8 & $0-3$ & 8.63 & 72.2 & 12.5 & 66.2 & 6.46 & 41.7 \\
\hline 9 & $0-3$ & 8.85 & 67.2 & 11.7 & 64.0 & 6.35 & 36.7 \\
\hline 10 & $0-3$ & 7.97 & 87.6 & 9.5 & 74.8 & 6.77 & 37.7 \\
\hline 11 & $0-3$ & 8.27 & 64.8 & 12.1 & 63.3 & 4.82 & 38.5 \\
\hline 12 & $0-3$ & 6.32 & 45.4 & 8.2 & 45.5 & 4.38 & 27.3 \\
\hline 13 & $0-3$ & 9.48 & 74.4 & 13.0 & 73.2 & 5.74 & 42.7 \\
\hline 14 & $0-3$ & 8.21 & 79.6 & 16.4 & 64.4 & 3.38 & 59.0 \\
\hline 15 & $0-3$ & 2.42 & 30.0 & 3.2 & 24.0 & 2.55 & 12.6 \\
\hline 16 & $0-3$ & 7.57 & 85.8 & 18.5 & 82.1 & 2.67 & 56.6 \\
\hline 17 & $0-3$ & 9.83 & 77.5 & 15.3 & 78.4 & 7.42 & 48.6 \\
\hline 18 & $0-3$ & 11.2 & 43.0 & 21.2 & 31.4 & 9.00 & 78.0 \\
\hline 19 & $0-3$ & na & na & na & na & na & na \\
\hline 20 & $0-3$ & 2.88 & 27.0 & 18.0 & 19.8 & 6.78 & 10.6 \\
\hline 21 & $0-3$ & na & na & na & na & na & na \\
\hline 22 & $0-3$ & na & na & na & na & na & na \\
\hline 23 & $0-3$ & 7.24 & 83.7 & 7.4 & 59.7 & 5.94 & 30.1 \\
\hline 24 & $0-3$ & 7.12 & 82.6 & 7.8 & 61.9 & 6.53 & 30.5 \\
\hline Average & & 8.31 & 67.9 & 13.7 & 61.1 & 5.99 & 41.6 \\
\hline SD & & 2.88 & 17.4 & 4.57 & 16.9 & 1.61 & 14.8 \\
\hline Max & & 17.3 & 87.6 & 21.2 & 82.1 & 9.0 & 78.0 \\
\hline Min & & 2.42 & 27.0 & 3.2 & 19.8 & 2.6 & 10.6 \\
\hline
\end{tabular}

$\mathrm{NA}=$ NotAnalyzed because of sample contamination; NA= NotAnalyzed because of the coarse sand sample; $S D=$ Standard Deviation; Max= Maximum; $M i n=$ Minimum

Table 2 : Geo-accumulation index values of analysed metals in sediments from Kuwait Marine Environment

\begin{tabular}{|c|c|c|c|c|c|c|c|c|c|c|c|c|}
\hline \multicolumn{2}{|c|}{ Station \# } & \multicolumn{5}{|c|}{$I_{\text {geo }}$ values based on Shale } & \multicolumn{6}{|c|}{$\mathrm{I}_{\mathrm{geo}}$ Class } \\
\hline & Co & $\mathrm{Cr}$ & $\mathrm{Cu}$ & $\mathrm{Ni}$ & $\mathrm{Pb}$ & $\mathrm{Zn}$ & Co & $\mathrm{Cr}$ & $\mathrm{Cu}$ & $\mathrm{Ni}$ & $\mathrm{Pb}$ & $\mathrm{Zn}$ \\
\hline 1 & -1.81 & -0.94 & -2.10 & -0.68 & -2.16 & -1.58 & 0 & 0 & 0 & 0 & 0 & 0 \\
\hline 2 & -1.64 & -0.83 & -2.35 & -0.47 & -2.26 & -1.76 & 0 & 0 & 0 & 0 & 0 & 0 \\
\hline 3 & -1.76 & -1.13 & -1.79 & -0.61 & -2.04 & -1.58 & 0 & 0 & 0 & 0 & 0 & 0 \\
\hline 4 & -1.74 & -0.88 & -2.18 & -0.55 & -2.17 & -1.58 & 0 & 0 & 0 & 0 & 0 & 0 \\
\hline 5 & -1.74 & -0.94 & -2.11 & -0.57 & -2.28 & -1.64 & 0 & 0 & 0 & 0 & 0 & 0 \\
\hline 6 & -0.72 & -0.95 & -2.02 & -0.67 & -1.98 & -1.58 & 0 & 0 & 0 & 0 & 0 & 0 \\
\hline 7 & -1.74 & -0.88 & -2.20 & -0.62 & -2.28 & -1.64 & 0 & 0 & 0 & 0 & 0 & \\
\hline 8 & -1.72 & -0.90 & -2.44 & -0.62 & -2.21 & -1.77 & 0 & 0 & 0 & 0 & 0 & 0 \\
\hline 9 & -1.69 & -1.01 & -2.52 & -0.67 & -2.24 & -1.96 & 0 & 0 & 0 & 0 & 0 & 0 \\
\hline 10 & -1.84 & -0.62 & -2.82 & -0.45 & -2.15 & -1.92 & 0 & 0 & 0 & 0 & 0 & 0 \\
\hline 11 & -3.55 & -1.06 & -2.48 & -0.69 & -2.64 & -1.89 & 0 & 0 & 0 & 0 & 0 & 0 \\
\hline 12 & -2.17 & -1.57 & -3.04 & -1.17 & -2.77 & -2.39 & 0 & 0 & 0 & 0 & 0 & 0 \\
\hline 13 & -1.59 & -0.86 & -2.38 & -0.48 & -1.11 & -1.74 & 0 & 0 & 0 & 0 & 0 & 0 \\
\hline 14 & -1.79 & -0.76 & -2.04 & -0.66 & -3.15 & -1.27 & 0 & 0 & 0 & 0 & 0 & 0 \\
\hline 15 & -3.56 & -2.17 & -4.39 & -2.09 & -3.55 & -3.49 & 0 & 0 & 0 & 0 & 0 & 0 \\
\hline 16 & -1.91 & -0.65 & -1.87 & -0.31 & -3.49 & -1.33 & 0 & 0 & 0 & 0 & 0 & 0 \\
\hline 17 & -1.68 & -0.93 & -2.28 & -0.51 & -2.30 & -1.67 & 0 & 0 & 0 & 0 & 0 & 0 \\
\hline 18 & -1.34 & -1.65 & -1.67 & -1.70 & 0.03 & -0.87 & 0 & 0 & 0 & 0 & 0 & 0 \\
\hline 20 & -3.31 & -2.32 & -1.91 & -2.36 & -2.14 & -3.75 & 0 & 0 & 0 & 0 & 0 & 0 \\
\hline 23 & -1.98 & -0.69 & -3.20 & -0.77 & -2.34 & -2.24 & 0 & 0 & 0 & 0 & 0 & 0 \\
\hline 24 & -2.00 & -0.71 & -3.12 & -0.72 & -2.20 & -2.22 & 0 & 0 & 0 & 0 & 0 & 0 \\
\hline
\end{tabular}




\section{Acknowledgments}

The authors would like to express their sincere gratitude to the Kuwait Foundation for the Advancement of Sciences (KFAS) for their financial support and to Kuwait Institute for Scientific Research (KISR) for their support and interst in this project.

\section{References}

Abrahim, G.M.S. and R.J. Parker: Assessment of heavy metal enrichment factors and the degree of contamination in marine sediments from Tamaki Estuary, Auckland, New Zealand. Environ. Monit. Assess., 136, 227-238 (2007).

Akcay, H., A. Oguz and C. Varlicly: Study of heavy metal pollution and speciation in Buyal Menderes and Gediz river sediments. Water Res., 37, 813-822 (2003).

Al-Muzaini, S.: Sewage discharge impact on the development of the Shuwaikh. Technology, 8, 51-54 (2002).

Al-Shamroukh, D.A., M. Arima and A. El-Sammak: Geochemical characteristics of intertidal sediments in Sulaibikhat Bay: Last 50 years, environmental changes in Kuwait. Proceedings of the Annual Meeting of the Japanese Association of Mineralogists, Petrologists and Economic Geologists (2005).

Alshemmari, H., Y. Al Otaibi and R. Owens: Trace metal concentrations in the surface sediments of Sulaibikhat Bay, Kuwait. Kuwait J. Sci. Eng., 37, 87-110 (2010).

Bharti, P.K.: Heavy Metals in Environment. Edition: First Publisher: Lambert Academic Publishing GmbH \& Co. KG, Saarbrucken, Germany (2012).

Caplat, C., H.Texier, D. Barillier and C. Lelievre: Heavy metals mobility in harbor contaminated sediments: The case of Port-en-Bessin. Mar. Pollut. Bull., 50,504-511 (2005).

Chen, F., J. Lin, B. Qian, Z. Wu, P. Huang, K. Chen, T. Li and M. Cai: Geochemical assessment and spatial analysis of heavy metals in the surface sediments in the eastern beibu gulf: A reflection on the industrial development of the South China Coast. Int. J. Environ. Res. Publ. Hlth., 15, 496 (2018)

Chester, R., A. Thomas, F.J. Lin, A.S. Basaham and G. Jacinto: The solid state speciation of copper in surface water particulates and oceanic sediments. Mar. Chem., 24, 261-292 (1988)

Cuvier, A., L. Pourcelot, A. Probst, J. Prunier and G. Le Roux: Trace elements and $\mathrm{Pb}$ isotopes in soils and sediments impacted by uranium mining. Sci. Total Environ., 566, 238-249 (2016)

Guevara-Rib, A., A. Sahuquillo, R. Rubio and G. Rauret: Assessment of metal mobility in dredged harbour sediment from Barcelona, Spain. Sci. Total Environ., 321, 241-255 (2004).

Guven, D.E. and G. Akinci: Heavy metals partitioning in the sediments of Izmir Inner Bay. J. Environ. Sci., 20, 413-418 (2008).

Han, L., B. Gao, X. Wei, L. Gao, D. Xu and K. Sun: The characteristic of $\mathrm{Pb}$ isotopic compositions in different chemical fractions in sediments from Three Gorges Reservoir, China Environ. Pollut., 206,627-635(2015)

Hlavay, J., T. Prohaska, M. Weisz, W.W. Wenzel and G.J. Stingeder: Determination of trace elements bound to soil and sediment fractions. Pure Appl. Chem., 76, 415-442 (2004).

Hudson-Edwards, K.A., M.G. Macklin, C.D. Curtisand and D. Vaughan: Mineralogical for metals, processes of formation and distribution of $\mathrm{Zn}, \mathrm{Cd}$ and $\mathrm{Cu}$ in the Tyne catchment basin, Northern Pennines, North EastEngland. Environ. Sci. Technol., 30, 72-80 (1996).
Idris, A.M., M.A.H. Eltayeb, S.S. Potgieter-Vermaak, R. Grieken and J.H. Potgieter: Assessment of heavy metal pollution in Sudanese harbours along the Red Sea coast. Microchemical, J., 87, 104-112 (2007).

Islam, M.S., M.K. Ahmed, M. Raknuzzaman, M.H. Al-Mamun and S. Masunaga: Metal speciation in sediment and their bioaccumulation in fish species of three urban rivers in Bangladesh. Ach. Environ. Contam. Toxicol., 68, 92-106 (2015).

Karbassi, A.R., S.M. Monavari, G.R. NabiBidhendi, J. Nouri and K. Nematpour: Metal pollution assessment of sediment and water in the Shur River. Environ. Monitor. Assess., 147, 107-116 (2008).

Katip, A., F. Karaer, S. Illeri, S. Sarmasik, N. Aydogan and S. Zenginay: Analysis and assessment of trace elements pollution in sediments of Lake Uluabat, Turkey. J. Environ. Biol., 33, 961-968 (2012).

Li, J., Y. Lu, H. Shim, X. Deng, J. Lian, Z. Jia and J. Li: Use of the BCR sequential extraction procedure for the study of metal availability to plants. J. Environ. Monitor., 12, 466-471 (2010).

Lulin, W., T. Mingzhong and W. Fadong: Discussion on the sedimentary structure, geochemical characteristics and sedimentary environment of Ping Chau formation at Tung Ping Chau, Hong Kong. J. Environ. Biol., 36, 777-788 (2015).

McAloon, K.M. and R.P. Mason: Investigations into the bioavailability and bioaccumulation of mercury and other trace metals to the sea cucumber, Sclerodactyl abriareus, using in-vitro solubilization. Mar. Pollut. Bull, 46, 1600-1608 (2003).

MOOPAM.: Manual of oceanographic observations and pollutant analyses methods. $4^{\text {th }}$ Edn., The Regional Organization for the Protection of the Marine Environment. Kuwait (2010).

Morillo, J., J. Usero and I. Gracia: Heavy metal distribution in marine sediments from the southwest coast of Spain. Chemosphere, $\mathbf{5 5}$, 431-442 (2004)

Müller, G.:Schwermle in den Sedimenten des Rheins - Veränderungen seit 1971. Umschan, 79, 778-783(1979).

Najamuddin and Surahman: Dispersion, speciation and pollution assessment of heavy metals and $\mathrm{Zn}$ in surface sediment from disturbed ecosystem of jeneberang waters. IOP Conf. Ser. Earth Environ. Sci., 89, 012030 (2017)

Qiao, Y., Y. Yang, J. Gu and J. Zhao: Distribution and geochemical speciation of heavy metals in sediments from coastal area suffered rapid urbanization, a case study of Shantou Bay, China. Mar. Pollut. Bull., 68, 140-146 (2013).

Romano, E., M.C. Magno and L. Bergamin: Grain size data analysis of marine sediments, from sampling to measuring and classifying. A critical review. IMEKO International Conference on Metrology for the Sea Naples, Italy, pp. 11-13 (2017).

Saleem, M., J. Iqbal and M.H. Shah: Geochemical speciation, anthropogenic contamination, risk assessment and source identification of selected metals in freshwater sediments-a case study from Mangla Lake, Pakistan. Environ. Nanotech. Monit. Manage., 4, 27-36 (2015).

Ure, A.M., C.M. Davidson and R.P. Thomas: Single and sequential extraction schemes for trace speciation in soil and sediment. In: Quality Assurance for Environmental Analysis: Method evaluation Within the Measurements and Testing programme (BCR) (Eds.: P. Quevauviller, E.A. Maier and B. Griepink). Vol. 17, 505-503 (1995)

Ure, A.M., Ph. Quevauviller, H. Muntau and B. Griepink: Speciation of heavy metals in soils and sediments. In: An Account of the Improvement and Harmonisation of Extration Technique Under taken the Auspices of the BCR of the commission of the european Communities. Int. J. Environ. Analy. Chem., 51, 135-515(1993). 